\title{
Measurements \& Detection Techniques in Nanotechnology in Road Applications
}

\author{
Hebatalrahman A. Hebatalrahman1, Saaid I. Zaki ${ }^{2}$ \\ ${ }^{1}$ Dr. Eng Consultant in Materials Science, Egypt \\ ${ }^{2}$ Strength and Testing of Materials, Housing and Building National Research Center, Cairo, Egypt \\ Email: Hebatalrahman11@yahoo.com, *saaid_zaki@yahoo.com
}

How to cite this paper: Hebatalrahman, H.A. and Zaki, S.I. (2020) Measurements \& Detection Techniques in Nanotechnology in Road Applications. World Journal of Nano Science and Engineering, 10, 37-50. https://doi.org/10.4236/wjnse.2020.103004

Received: August 18, 2020

Accepted: September 27, 2020

Published: September 30, 2020

Copyright $\odot 2020$ by author(s) and Scientific Research Publishing Inc. This work is licensed under the Creative Commons Attribution International License (CC BY 4.0).

http://creativecommons.org/licenses/by/4.0/

(c) (i) Open Access

\begin{abstract}
In recent years, the world of science has started to produce advanced materials and technology in the nanoscale, which known as nanotechnology. The use of nanotechnology has become wide spread in all branches of science, one of the important branches is the field of transportation. The application of nanotechnology in pavements showed great promise and the potential to change commonly used materials, which makes transportation more efficient, smart looking, stronger and durable that all lead to the extension of their life cycle of the roads. So, there is an essential need to prepare advanced nanotechnology tools and detection systems contain very recent instruments needed for nanotechnology studies, since the physical, chemical and biological properties of the material at nanoscale differ in fundamental and valuable ways from that at normal scale. In this work the different techniques in measuring and detection techniques in nanotechnology will be discussed the method of operation and accuracy of each technique will be evaluated, the main applications of each technique in industrial and construction field will be evaluated.
\end{abstract}

\section{Keywords}

Nanotechnology, Detection, Equipment's, Accuracy, Transportation,

Pavements, Roads

\section{Introduction}

\section{Necessity of Present Work:}

This study focused on the state of art of using nanotechnology in enhancement of transportations and pavements.

- Helel et al. (2016) [1], carried out M.Sc. Thesis about "The performance of Asphalt binder enhanced with nanomaterials" and found that: Asphalt resis- 
tance to permanent deformation enhanced using the right content of nano-modifier (3\% nano clay and 7\% N S F by weight of asphalt).

- Arpit et al. (2015) [2], published an article about "Overview of nanotechnology in Road Engineering", and found that: The application of nanotechnology can improve the overall competitiveness of the Road Engineering Industry.

- Helal et al. (2018) [3], carried out an investigation about "Predicted performance of hot mix asphalt modified with nano-montmorillonite and nano silicon dioxide based on Egyptian conditions" and found that: The nano-modified mixes showed better AC (Asphalt Concrete) layer rutting resistance compared to control mix, furthermore, the 3\% NMMT (nano-montmorillonite) modified mix exhibited better AC rutting resistance compared to the other investigated mixes.

- Faruqi (2015) [4], published an article about "State-of-the-art review of applications of nanotechnology in pavement materials", and concluded that: It is observed from this review that nanotechnology can help to improve the performance of transportation construction materials and this may eventually lead to the extension of their life cycle.

- Helal et al. (2016) [5], carried out an investigation about "Evaluation of Asphalt binders modified with nano clay and nano-silica", and found that nano-silica synthesized from silica fume tends to decrease the penetration value and increases the softening point temperature, while nano clay increase the penetration value and decrease the softening point temperature, also the Dynamic Shear Rheometer (DSR) results showed obvious improvement in the performance grade leading to higher resistance to permanent deformation.

- Jinu et al. (2019) [6], published A. Review "Potential Applications of nanotechnology in Transportation" and concluded that: Nanotechnology in the field of transportation will put an imprint in the development of our society, since significant improvements in comfort, safety and economy in transportation systems will be achieved simultaneously when nanotechnology will be applied, which make pavements more efficient, smart looking, stronger and durable.

- Helal et al. (2016) [7], carried out an investigation about "Evaluation of Asphalt Enhanced with Locally Made Nanomaterials" and found that:

- Hot Asphalt mixtures prepared by using 7\% NSF (Nano Silica Fume) had better Marshall Stability and loss of stability that that obtained by control hot asphalt mixtures (H M A).

- Hot Asphalt mixtures prepared using 3\% nano clay had improved also Marshall stability than control (H M A) but with higher loss of stability.

Nanomaterials have different applications in modern life as shown in Figure 1

[8] [9]. This study is aiming to achieve the following purposes:

- Helping in finding the right way, of using the nanomaterials in construction development and transportation field. 


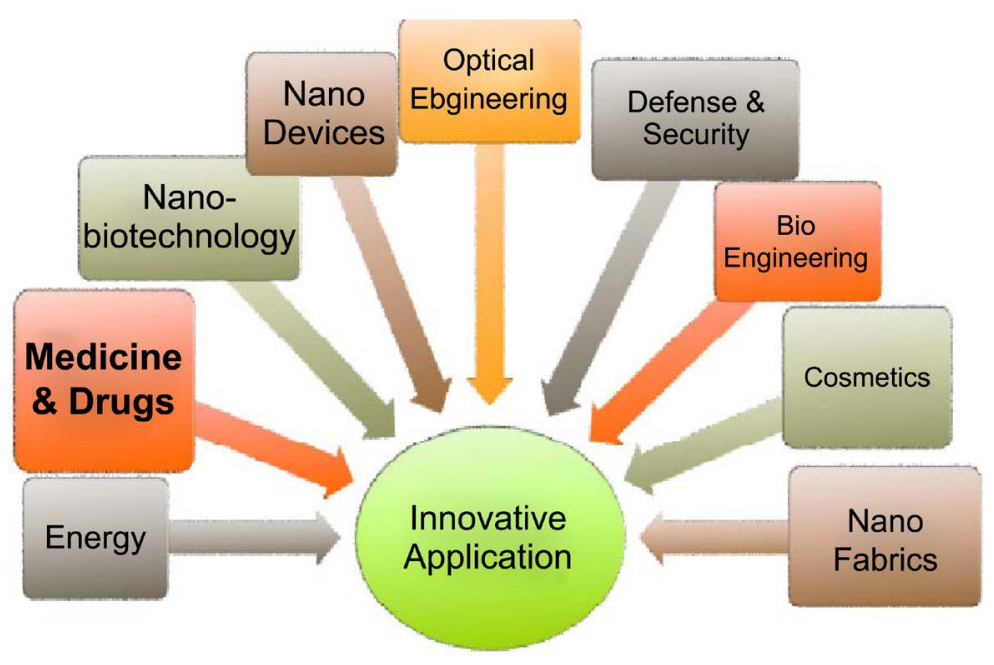

Figure 1. Innovative application of nanotechnology [8] [9].

- Guiding in finding of an external application (in organizations, factories and companies), which related to construction process [10] [11].

The Nanotechnology in building and construction fields are planned to achieve the following aims:

1) Synthesizing and preparing of the required Nanomaterials [12].

2) Dealing with the Nanomaterials in different applications.

3) Enhancement the properties of pavements using nanomaterials.

4) Enhancement the properties of steel using nanomaterials.

5) Production of smart concrete and smart building and smart transportation [13] [14] [15] [16] [17].

6) Improvements of glasses to increase daylighting and decreasing thermal effect using nano $\mathrm{TiO}_{2}$.

7) Purification of drinking water using nano membranes [18].

8) Development of energy efficiency in building using nanotechnology.

9) Improving the efficiency of the components used in solar systems for generating electricity using nanotechnology [19] [20].

The above goals will need developing methods such as:

- New preparing method to achieve the size, shape and mode of the used nanomaterials that causes the required effect [21] [22].

- The suitable method of using nanomaterials in coating, doping, matrix and interfaces [23] [24].

- The tools that helping in achieving the above items.

- Precautions that could be taken into consideration through working in each item [25] [26].

\section{Measurements and Detection Techniques in} Nano-Technology

Nano Indenter

1) The Nano Indenter Apparatus 
It enables Users to perform and understand mechanical tests on the micro and nano scales as shown in Figure 2(a), Figure 2(b).

Surface and near-surface mechanical properties of thin films and coatings can be critical to their final performance. The rapidly expanding field of depth-sensing nanoindentation provides a quantitative method for mapping the mechanical properties, such as hardness and elastic modulus, of the surface/near-surface region. Quantification is possible through the use of diamond indenters with welldefined tip geometry, combined with established models for determining the mechanical properties from the measured data. Nanoindentation has been employed extensively to characterize the mechanical properties of a wide range of hard coatings and surface-modified layers. The principle behind nanoindentation is similar to micro hardness testing, which employs greater applied load so that the residual indent can be measured optically [27].

The nano test is a system depends on the electromagnetic sensing technique, The electrical current in coil leads to generation of electromagnetic field, it is cause the rotation motion of pendulum on its central axis and the friction force is eliminated, movement of pendulum leads to the surface penetration by diamond test probe, The displacement of the diamond probe is measured on the

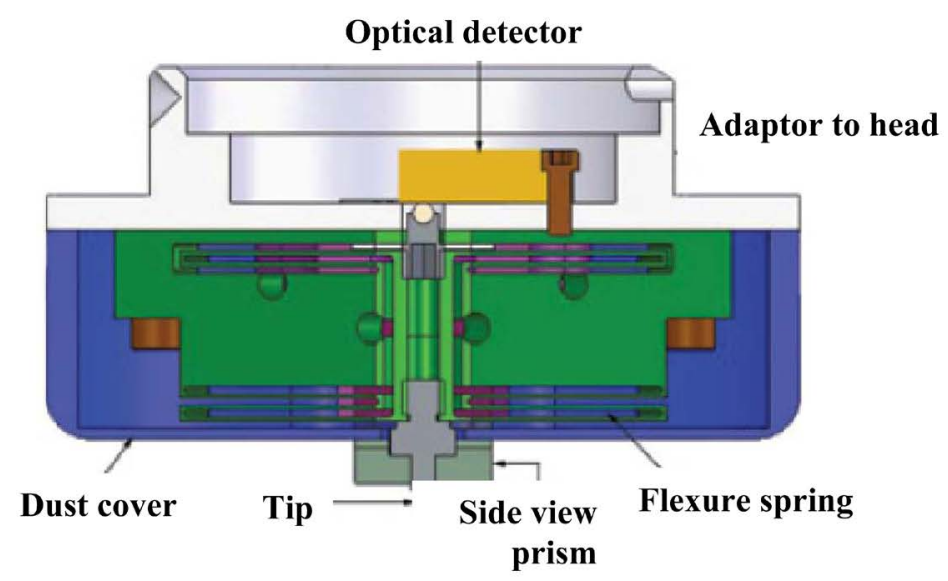

(a)

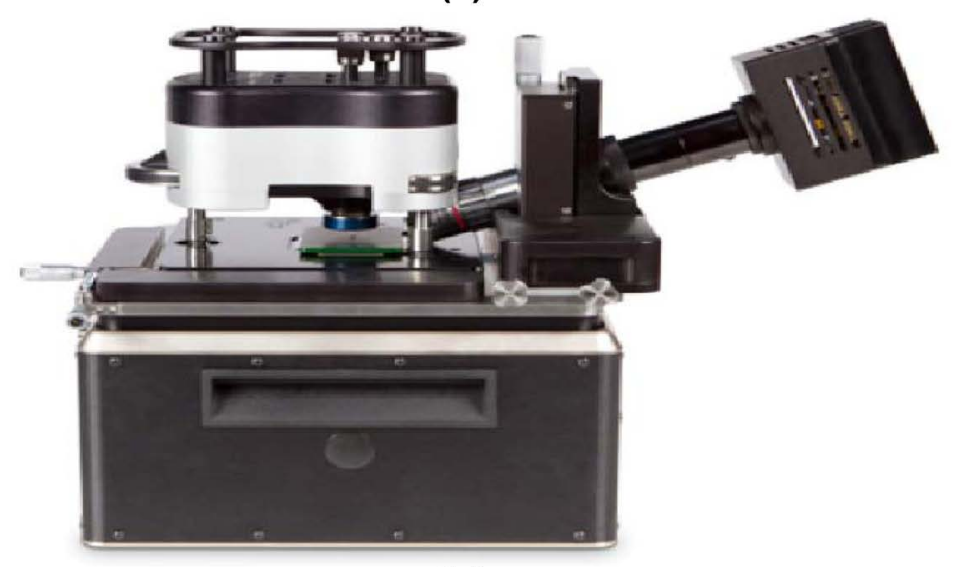

(b)

Figure 2. (a) (b) The nano indenter apparatus. 
nanometer scale by electrical sensor, the sensor consists of capacitor with parallel plates [28].

A Berkovich (three-sided pyramidal) diamond indenter was used for all the indentation testing. In view of the rounding of the indenter at the tip, it is necessary to determine the area function of the indenter to obtain meaningful values of hardness and modulus. The area function for the diamond, which is used to determine the contact area for a given depth, was calibrated by indentations to different depths into fused quartz (load range: $0.5-200 \mathrm{mN}$ ). Fused quartz is an isotropic material used as a calibration standard by the nanoindentation community because its hardness and elastic modulus do not vary significantly with indentation depth. The area function for the diamond used in this work was $A=23.1 h_{c}^{2}+1278 h_{c}$, where $h_{c}$ is the contact depth. For comparison, the area function of an ideal Berkovich diamond is $A=24.5 h^{2}$. Fused quartz was also used to determine the instrument (frame) compliance, which was $0.81 \mathrm{~nm} / \mathrm{mN}$ for the instrument used in this work. The measured depth is adjusted for the effect of instrument compliance in the instrument software [29].

\section{2) Indentation Data Analysis}

The depth vs. load raw unloading data was fitted to a power-law function, as originally proposed by Oliver and Pharr [W. C. Oliver, G. M. Pharr, J. Mater. Res. 7 (1992) p. 1564], to determine the hardness and modulus of the film, after correction for the effects of instrument compliance

Contact compliance $C=$ total compliance $\left(C_{t}\right)$ - machine compliance $\left(C_{m}\right)$ where contact compliance $=1 /$ contact stiffness. The power-law function has the form

$$
P=a\left(h-h_{f}\right)^{m}
$$

where $P$ is the load, $\left(h-h_{f}\right)$ is the elastic displacement, $a$ and $m$ are material constants. The indenter contact (or plastic) depth, $h_{c}$ is determined from the expression:

$$
h_{c}=h_{\max }-v\left(C P_{\max }\right)
$$

where $C$ is the contact compliance equal to the tangent at maximum load $\left(P_{\max }\right)$. The value of $v$ is a function of the indenter geometry and depends on the pressure distribution that is established after the plastic deformation. For flat punch indenter $v$ is 1 , whereas for a Berkovich indenter, as used in this study, $v$ is taken as 0.75 since most indenters have a rounded tip. The plastic depths correspond to these indenter geometries. The diamond area function $A\left(h_{c}\right)$ was determined separately from indentations into fused quartz.

The hardness $(H)$ is determined from the peak load $\left(P_{\max }\right)$ and the projected area of contact, $A$ :

$$
H=P_{\max } / A
$$

To obtain the elastic modulus, the unloading portion of the depth-load curve is analyzed according to a relation, which depends on the contact area: 


$$
C=v^{0.5} /\left(2 E_{r} A^{0.5}\right)
$$

where $\mathrm{C}$ is the contact compliance and $E_{r}$ is the reduced modulus defined by

$$
1 / E_{r}=\left(1-v_{s}^{2}\right) / E_{s}+\left(1-v_{i}^{2}\right) / E_{i}
$$

where $v_{s}$ the Poisson's ratio for the sample, $V_{p}$ the Poisson's ratio for the indenter (0.07), $E_{s}$ the Young's modulus for the sample and $E_{p}$, the Young's modulus for the indenter $(1141 \mathrm{GPa})$.

In all the data reported in this paper, the loading data have been fitted to a power-law function in the instrument software to determine this depth offset, as has been done previously.

$$
P=a\left(h-h_{0}\right)^{n}
$$

where $P$ is the load, $h_{0}$, the real depth zero, $a$, a material parameter and $n$, the index of the deformation (indentation exponent).

The mechanical properties such as hardness, stiffness and reduced modulus of nano layers and thin films can be measured by nano indentation techniques. (Nano-test 600 instrument), the diamond probe in the shape of pyramid with three side edges is the indentation tool, the peak loads are the main parameters in the measurements,

The loading rate is equal to the unloading rate of the capacitor so it gives the required indication [30] [31].

Minimum value for 1 indentation and experimental conditions as initial (contact) load and holding period at peak load at specific time were used for all the measurements. The indentations were repeated at least five times at each load on different regions of the sample surface apart with specific distance [32].

Two scientists called Oliver and Pharr invent fitting technique relate the power of unloading curve to the indentation resulting from different loads so the mechanical properties such as hardness, stiffness and reduced modulus can be measured by nano-indentation technique [33].

3) The Nano Indenter Benefits

The most important technique in the nanoworld measurements is the nano indenter because it is unique in measuring mechanical properties; it has different application in plastics, new materials, composite materials, Lithography, electronics, Manipulation and life science

The main advantages are:

- Standardized measurements of Young's modulus and hardness according to ISO 14577 [31].

- Controlled and quantitative scratch testing. In addition to Quick and easy results with little sample preparation.

- Unparalleled dynamic range in force and displacement.

- Support from a world-renowned scientific staff. A platform that expands with your testing needs to allow: frequency-specific test, quantitative scratch testing, integrated AFM-style imaging, high-temperature testing, expanded load capacity up to $10 \mathrm{~N}$. 
- Custom experiments and user-friendly finite-element simulations [30].

\section{Atomic Force Microscope}

The Atomic Force microscope is one of the most important technique in nano world, it is mainly used as qualitative analysis technique, the ultra-high-resolution photos resulting from (AFM) technique are very important in different nano-materials application as shown in Figures 3(a)-(c), it is the most important technique in the atomic resolution scale [18] [32].

\section{The Nano Particle Size Analyzer}

This tool is designed to measure the size of the particle in nano scale addition of Measurement of the zeta potential

Measuring of zeta potential is important for determining the effectiveness of the stabilization of a colloidal system by electric charge, thus reducing the possibility of aggregation. Particulate dispersions can be designed to be colloidally stable by controlling chemical parameters in both the dispersed and continuous (solvent) phases, which directly affect electrostatic repulsions. The NICOMP 380/ZLS instrument provides the colloidal chemist with an important tool for measuring the zeta potential of a wide variety of particulate dispersions. Our simple, innovative design has yielded a product which is equally effective in both the research lab and production environment [18] [25].

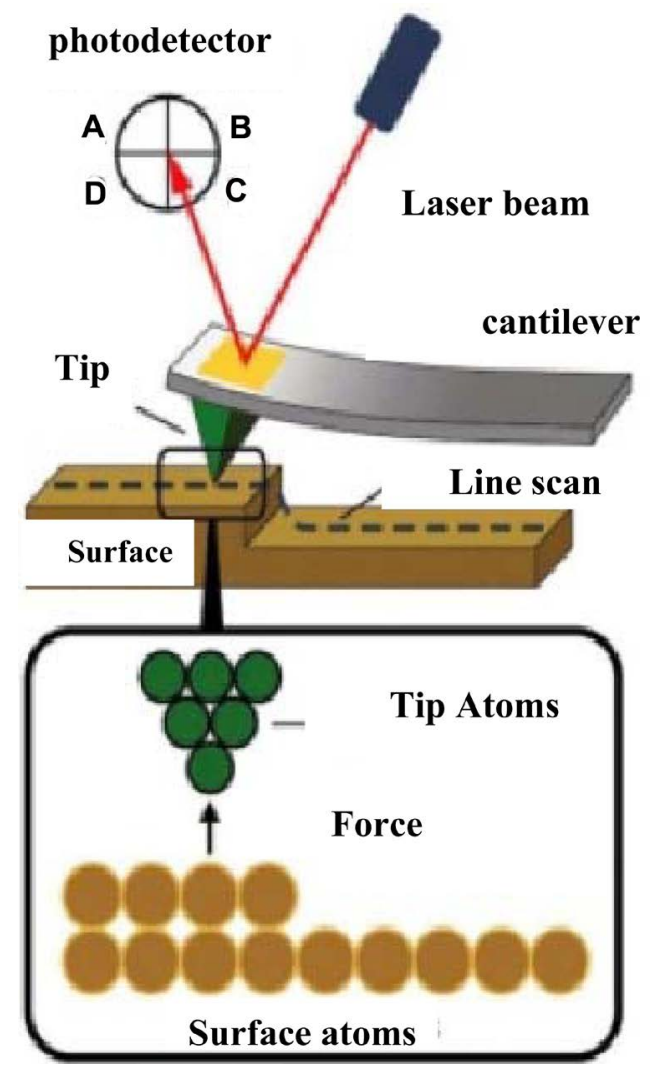

(a) 


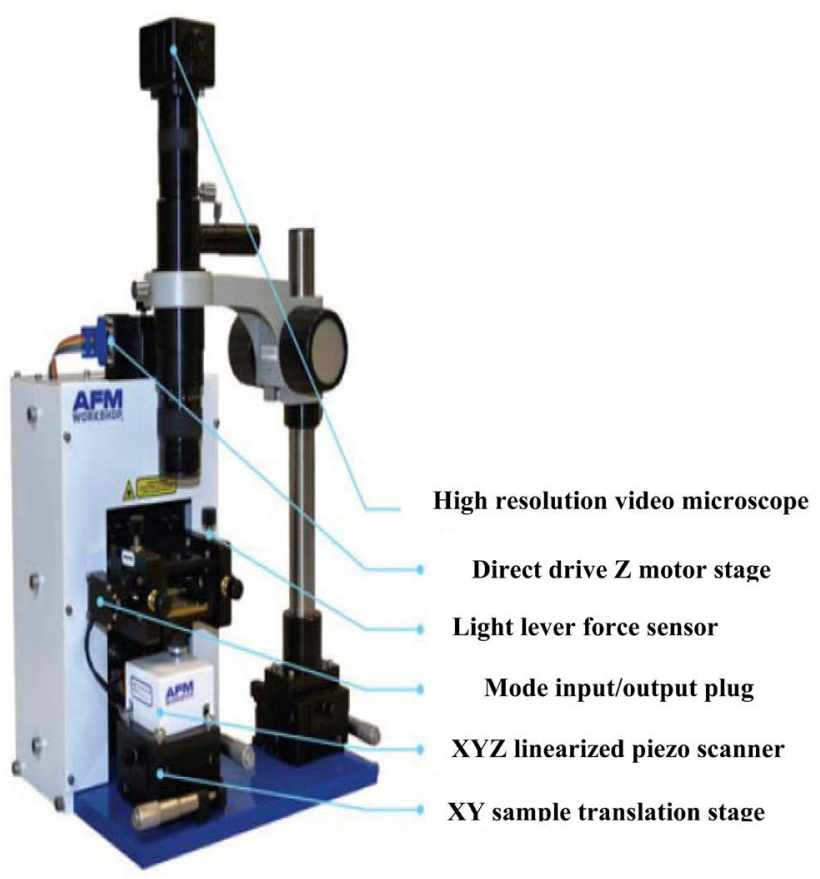

(b)

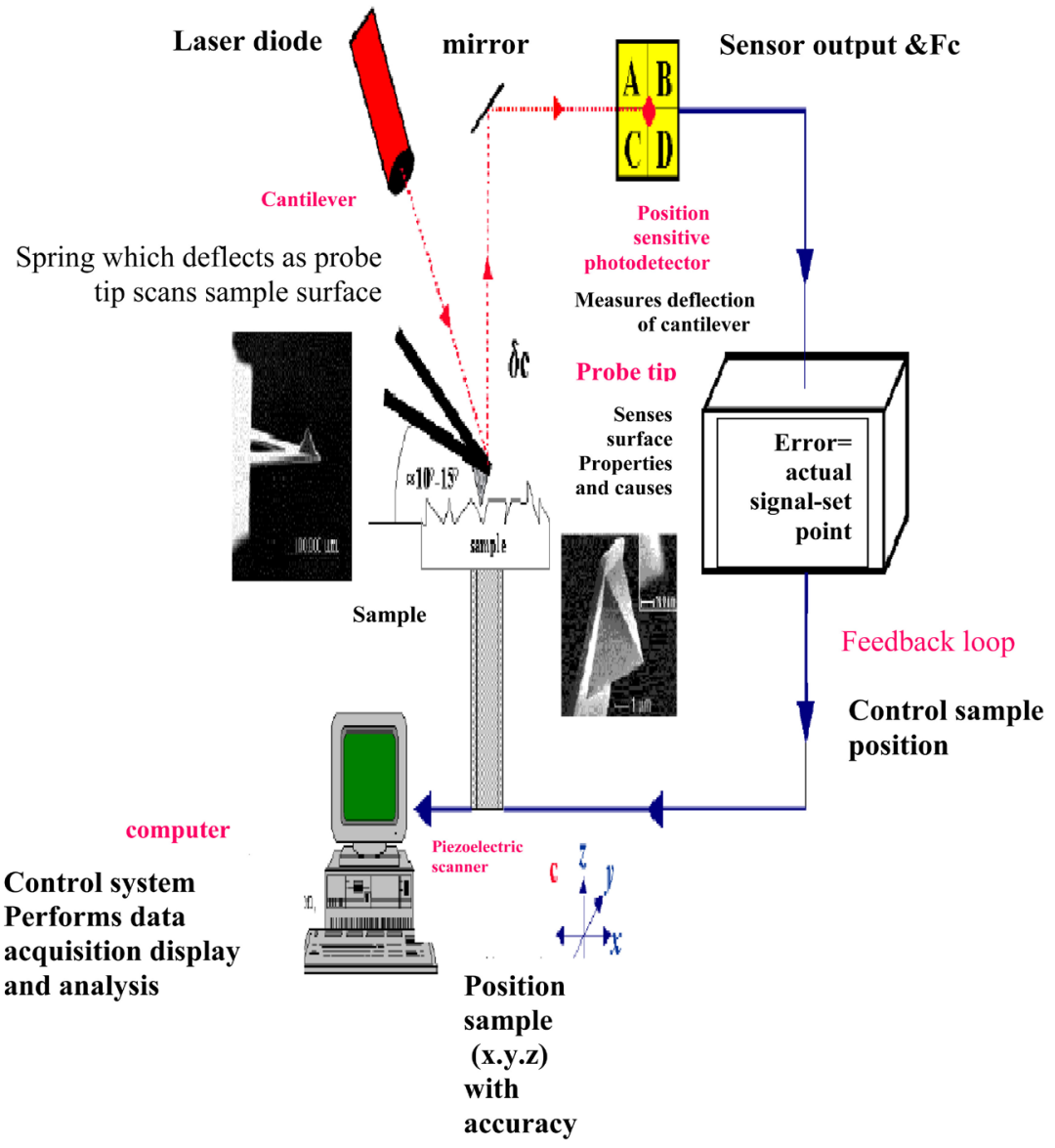

(c)

Figure 3. (a) Operation technique in AFM; (b) General Components of (AFM); (c) Setup of (AFM). (a) (b) (c) Atomic Force Microscopy (AFM) General Components. 


\section{Zeta Potential}

Zeta potential is measurement technique to determined surface of charged colloids with accuracy of the Zeta potential is $+20 \mathrm{mV}$, in other words the Zeta potential can be used to evaluate particle concentration, distribution, adsorption, ionization and so on. The different manufacturing parameters such as particle stability, Basicity $(\mathrm{PH})$, bio compatibility, temperature, circulation time and other parameters can be determined by zeta potential [26].

To understand the Zeta potential technique which shown in Figure 4 and its importance in the industry, nanotechnology and nano-science let us give example about Zeta potential application, in paper industry the amount of additives is very important factors specially cationic and anionic, Zeta potential is also very important technique during storage technique of materials, it can be used to evaluate the changes in characteristic during storage which can affect its characteristics [29] [30].

A double layer exists around each particle. If a particle is negatively charged a thin layer of positive charge forms around the particles (the stem layer). Beyond
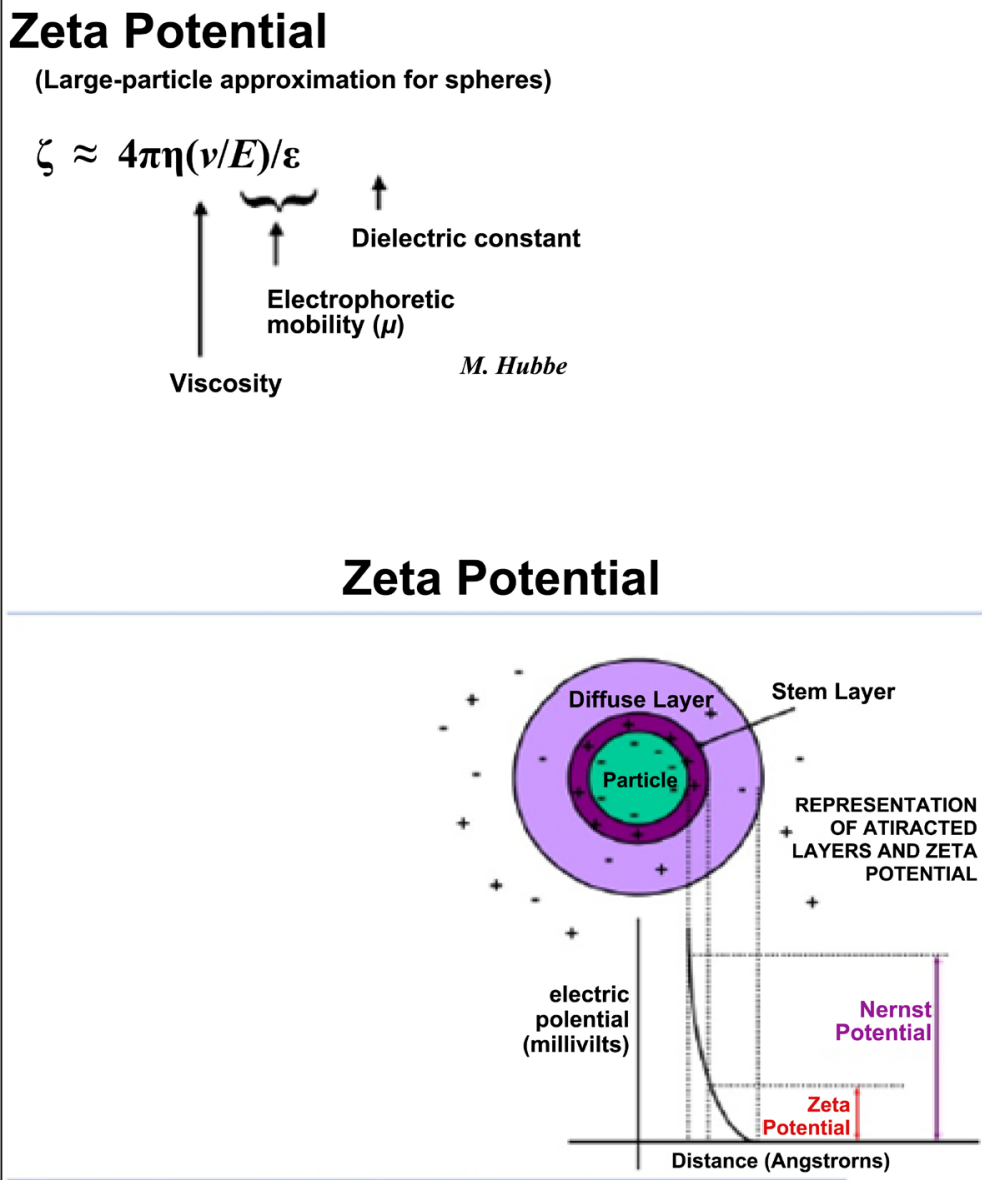

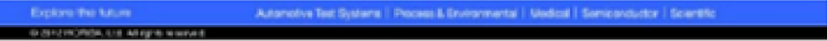

Figure 4. Zeta potential. 
the stem layer, there is a wider layer of mostly opposite charge known as the diffuse layer.

The potential at the surface of the particle is designated the NERNST potential and the potential at the shear plane is designated the ZETA potential.

ZETA potential is a useful measurement quantity because it is measure of surface activity in colloidal particles

\section{Scanning Tunneling Microscope (STM)}

The concept in the working theory of (STM) is the detection of the current go through the circuit between the tip and substrate. In these techniques both the scanning tip and the substrate must be made from conducting materials such as metals and metal-based materials [29] [33].

The process is controlled by computer and piezo electric effect element such as piezo robot. The main parameter must be controlled is the distance (d) between metallic scanning tip and conducting substrate. The output feedback voltage resulting from the closed circuit between tip and substrate is the main indication value of the quality of the scanning technique as shown in Figure 5.

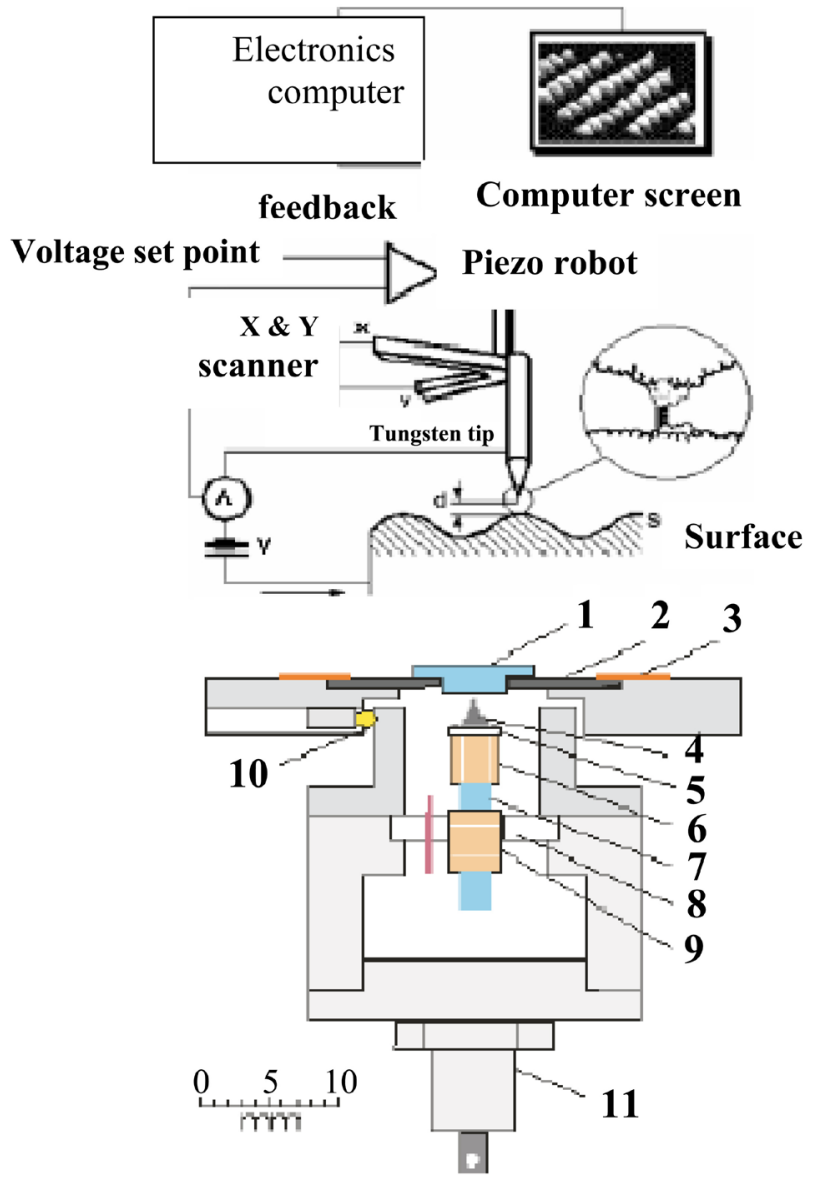

Figure 5. Scanning tunneling microscopy (STM). (1) Sample, (2) Sample holder, (3) Clamps, (4) Tip, (5) Tip holder, (6) Piezoelectric scanner tube, (7) Approach motor rod, (8) Motor mount, (9) Approach mount, (10) Quartz balls, and (11) Zener Diode. 


\section{Comparing Different Techniques}

The most important techniques in the nano-technology world detection are discussed above, Table 1 shows comparison between different techniques according to function and operation technique.

Table 1. Comparing between different techniques.

\begin{tabular}{|c|c|c|c|c|}
\hline No & Name & Idea of work & Function & Notice \\
\hline 1 & Nano Indenter Apparatus & $\begin{array}{l}\text { applied load affect indentor so } \\
\text { residual indent can be measured } \\
\text { optically }\end{array}$ & $\begin{array}{l}\text { Measure mechanical properties } \\
\text { (reduced modulus, hardness, stiffness) }\end{array}$ & $\begin{array}{l}\text { the electromagnetic sensing } \\
\text { technique, the electrical current } \\
\text { in coil leads to generation of } \\
\text { electromagnetic field }\end{array}$ \\
\hline 2 & Atomic Force Microscope & $\begin{array}{l}\text { Optical system with ultra-high } \\
\text { resolution }\end{array}$ & $\begin{array}{l}\text { qualitative analysis technique for high } \\
\text { resolution photos }\end{array}$ & \\
\hline 3 & Nano particle size analyzer & $\begin{array}{l}\text { stabilization of a colloidal system } \\
\text { by electric charge }\end{array}$ & $\begin{array}{l}\text { measure the size of the particle in } \\
\text { nano scale }\end{array}$ & \\
\hline 4 & Zeta Potential & $\begin{array}{l}\text { determined surface of charged } \\
\text { colloids with accuracy of the Zeta } \\
\text { potential is }+20 \mathrm{mV}\end{array}$ & $\begin{array}{l}\text { evaluate particle concentration, } \\
\text { distribution, adsorption, ionization } \\
\text { particle stability, Basicity }(\mathrm{PH}) \text {, bio } \\
\text { compatibility, temperature, } \\
\text { circulation time }\end{array}$ & $\begin{array}{l}\text { determined surface of charged } \\
\text { colloids }\end{array}$ \\
\hline 5 & $\begin{array}{l}\text { Scanning Tunneling } \\
\text { Microscope (STM) }\end{array}$ & $\begin{array}{l}\text { The output feedback voltage } \\
\text { resulting from the closed circuit } \\
\text { between tip and substrate is the } \\
\text { main indication of the quality }\end{array}$ & Scanning and processing of metal & $\begin{array}{l}\text { Used as manufacturing method } \\
\text { beside scanning }\end{array}$ \\
\hline
\end{tabular}

\section{Conclusions \& Recommendations}

1) The application of nanotechnology in pavements showed great promise and potential to change commonly used materials which make transportation more efficient, smart, stronger and durable, which all lead to the extension of the life cycle of the roads.

2) The state-of-the-art review of application of nanotechnology in pavements and transportation showed that: nanotechnology can help to improve the performance of transportation construction materials which leads to improve competitiveness of the road engineering industry.

3) Application of nanotechnology in the field of transportation will put an imprint in the development of our society, since significant improvement will be achieved in comfort, safety and economy of transportation systems simultaneously when nanotechnology will be applied.

4) There is an essential need to prepare advanced nanotechnology tools and detection systems, contain very recent instruments needed for nanotechnology studies, since the physical, chemical and biological properties of the material at nanoscale differ in fundamental and valuable ways from that at normal scale.

5) The new techniques are Nanoindentation techniques, which evaluate the mechanical properties of the nano-materials such as reduced modulus, stiffness and Hardness. 
6) Atomic Force Microscope is the most important tool for Nano Technology, it is commonly known as the eye of nano and it's served all Nano Technology Applications. So, the AFM is measuring tool at Nano Scale which can give us the ultra-High-resolution Image which can reach to atomic resolution and also high-resolution measurements at nanoscale.

7) The size and shape of the nanoparticles can be determined in terms of distance, the theory of equipment work depends on electrical repulsive force, the Zeta potential technique is considered as the best evaluation for the force magnitude and direction.

\section{Conflicts of Interest}

The authors declare no conflicts of interest regarding the publication of this paper.

\section{References}

[1] Helel, E. (2016) The Performance of Asphalt Binder Enhanced with Nano Materials. M.Sc. Thesis, Mansoura University, Mansoura.

[2] Arpit, S., et al. (2015) Overview of Nanotechnology in Road Engineering. Journal of Nano- and Electronic Physics, 7, Article No. 02004.

[3] Ezzat, H., El-Badawy, S., Gabr, A., Zaki, S. and Breakah, T. (2018) Predicted Performance of Hot Mix Asphalt Modified with Nano-Montmorillonite and Nano Silicon Dioxide Based on Egyptian Conditions. International Journal of Pavement Engineering, 21, 642-652. https://doi.org/10.1080/10298436.2018.1502437

[4] Faruqi, M., Castillo, L. and Sai, J. (2015) State-of the-Art Review of Applications of Nanotechnology in Pavement Materials. Journal of Civil Engineering Research, 5, 21-27.

[5] Helal, E., Sherif, E., Alaa, G., Zaki, S.I. and Tamer, B. (2016) Evaluation of Asphalt Binders Modified with Nanoclay and Nanosilica. Procedia Engineering, 143, 1260-1267. https://doi.org/10.1016/j.proeng.2016.06.119

[6] Jinu, M., Josny, J. and Soney, C. (2019) Potential Applications of Nanotechnology in Transportation: A Review. Journal of King Saud University: Science, 31, 586-594. https://doi.org/10.1016/j.jksus.2018.03.015

[7] Helal, E., Sherif, E., Alaa, G. and Zaki, S.I. (2016) Evaluation of Asphalt Enhanced with Locally Made Nanomaterials. Nano-Technologies in Constructions, Scientific Internet Journal, 8, 42-67. https://doi.org/10.15828/2075-8545-2016-8-4-42-67

[8] Hebatalrahman, H.A. (2008) New Method for Laser Treatment of Titanium Alloys \& Other Materials. Patent No. 24014.

[9] Nordgren, E.J., Butorin, S.M., Duda, L.C., Guo, J.-H. and Rubensson, J.-E. (2002) Chapter 10: Soft X-Ray Fluorescence Spectroscopy for Materials Science and Chemical Physics. In: Sham, T.-S., Ed., Chemical Applications of Synchrotron Radiation, World Scientific Publishing, Singapore, 517-572.

https://doi.org/10.1142/9789812775757_0010

[10] Guo, J. (2006) Chapter 8: X-Ray Absorption and Emission Spectroscopy in Nanoscience and Life Sciences. In: Kumar, C., Ed., Nano System Characterization Tools in the Life Sciences, Wiley-VCH Verlag GmbH, Weinheim, 259-291.

[11] Nordgren, E.J., Butorin, S.M., Duda, L.-C. and Guo, J.-H. (2007) Chapter 14: Soft 
X-Ray Emission and Resonant Inelastic X-Ray Scattering Spectroscopy. In: Vij, D., Ed., Handbook of Applied Solid-State Spectroscopy, Springer, Boston, 595-659. https://doi.org/10.1007/0-387-37590-2_14

[12] Hebatalrahman, H.A. (2012) Laser Treated Hybrid Composite Material for Fire Resistance Applications. Patent No. 24615.

http://www.egypo.gov.eg/inner/english/.../egyptian_patent_abstract_3_2010_e.pdf

[13] Hebatalrahman A. Hebatalrahman (2012) Simplified Technique for Recycling of Microand Nano-Composite. https://doi.org/10.21608/amme.2012.36944

[14] Ahmed, H. (2010) Nano Indentation Effects on SS 316L During Excimer Laser Irradiation. Journal of Physics, 1, 34-39.

[15] Hebatalrahman, H.A. (2012) New Method for Fabrication and Laser Treatment of Nano-Composites. Journal of American Science, 6, 149-154. http://www.yumpu.com/en/.../full-text-nature-and-science

[16] Butorin, S.M. (2000) Resonant Inelastic X-Ray Scattering as a Probe of Optical Scale Excitations in Strongly Electron-Correlated Systems: Quasi-Localized View. Journal of Electron Spectroscopy and Related Phenomena, 110-111, 213-233. https://doi.org/10.1016/S0368-2048(00)00166-3

[17] Oppenheimer, A. (2005) Nanotechnology Paves Way for New Weapons. http://www.hartford-hwp.com/archives/27a/317.html

[18] Osakabe, N., Harada, K., Lutwyche, M.I., Kasai, H. and Tonomura, A. (1997) Time-Resolved Observation of Thermal Oscillations by Transmission Electron Microscopy. Applied Physics Letters, 70, 940-942. https://doi.org/10.1063/1.118447

[19] Overbye, D. (2008) Gauging a Collider's Odds of Creating a Black Hole. http://www.nytimes.com/2008/04/15/science/15risk.html

[20] Wei, P.Z., et al. (2001) Nanobelts of Semiconducting Oxides. Science, 291, 19471949. https://doi.org/10.1126/science. 1058120

[21] Pankhurst, Q.A., Connolly, J., Jones, S.K. and Dobson, J. (2003) Applications of Magnetic Nanoparticles in Biomedicine. Journal of Physics D: Applied Physics, 36, R167-R181. https://doi.org/10.1088/0022-3727/36/13/201

[22] Parak, W.J., Pellegrino, T. and Plank, C. (2005) Labelling of Cells with Quantum Dots. Nanotechnology, 16, R9-R25. https://doi.org/10.1088/0957-4484/16/2/R01

[23] Parent, W.A. (1983) Privacy, Morality and the Law. Philosophy \& Public Affairs, 12, 269-288.

[24] Parfit, D. (1986) Reasons and Persons. Oxford University Press, New York. https://doi.org/10.1093/019824908X.001.0001

[25] Ho, H., et al. (2008) Contact Lens with Integrated Inorganic Semiconductor Devices. 21 st IEEE International Conference on Micro Electro Mechanical Systems, Wuhan, 13-17 January 2008, 403-406. https://doi.org/10.1109/MEMSYS.2008.4443678

[26] Charles Sanders, P. (1934) The Fixation of Belief. In: Hartshorne, C. and Weiss, P., Eds., Collected Papers of Charles Peirce, Harvard University Press, Cambridge, 223-247.

[27] Qui, P.F, Vermesh, O., Grecu, M., Javey, A., Wang, Q., Dai, H.J., Peng, S. and Cho, K.J. (2003) Toward Large Arrays of Multiplex Functionalized Carbon Nanotube Sensors for Highly Sensitive and Selective Molecular Detection. Nano Letters, 3, 347-351. https://doi.org/10.1021/nl034010k

[28] Raj, P. (2006) Does Smarter Mean Happier? In: Miller, P. and Wilsdon, J., Eds., 
Better Humans. The Politics of Human Enhancement and Life Extension, Demos, London, 129-136.

[29] Peslak, A.R. (2005) An Ethical Exploration of Privacy and Radio Frequency Identification. Journal of Business Ethics, 59, 327-345.

https://doi.org/10.1007/s10551-005-2928-8

[30] Philipkowski, K. (1999) Another Change for Gene Therapy. http://www.wired.com/science/discoveries/news/1999/10/31613

[31] Plato (1968) Laws, Plato in Twelve Volumes. Harvard University Press, Cambridge, $739 c-d$.

[32] Plato (1992) The Republic. 2nd Edition, Hackett Publishing Company, Indianapolis.

[33] Plato (2008) Critics. http://classics.mit.edu/Plato/critias.html 